\title{
Does intrauterine tobacco exposure increase the pain perception of newborns?
}

\author{
Mustafa Tekin \\ Șule Yıldırım \\ Hakan Aylanç \\ Nazan Kaymaz \\ Fatih Battal \\ Naci Topaloğlu \\ Esra Bașer \\ Fatih Köksal Binnetoğlu
}

Department of Pediatrics, Faculty of Medicine, Çanakkale Onsekiz Mart

University, Çanakkale, Turkey
Correspondence: Șule Yıldırım Department of Pediatrics, Faculty of Medicine, Çanakkale Onsekiz Mart University Hospital, Cumhuriyet Mahallesi, 5 Sahil Yolu, Kepez, Çanakkale, I7I00 Turkey

Tel +902862635950

Fax +902862635956

Email sule.yildirim@yahoo.com
This article was published in the following Dove Press journal:

Journal of Pain Research

3I May 2016

Number of times this article has been viewed

Background: This study aimed to assess whether there was a difference in the pain-perception levels of newborns born to mothers who smoked during pregnancy and newborns born to mothers who were not exposed to active or passive smoking during pregnancy.

Materials and methods: A total of 60 newborns born by normal spontaneous vaginal birth between June 2013 and June 2014 were included in the study: 30 born to mothers who smoked during pregnancy, and 30 born to mothers not exposed to smoking. Mothers or newborns who had taken analgesics or sedative medications in the previous 24 hours, newborns not born at term, and sick newborns were not included in the study. During the routine hepatitis B-vaccination injection given at postnatal 48 hours, the newborns' behavior was monitored and recorded by video camera. The data obtained from the recordings were evaluated according to the Neonatal Pain, Agitation, and Sedation Scale and analyzed with SPSS 20.

Results: The median pain score of the group exposed to tobacco smoke in utero was 8.5 , while the median pain score of the unexposed group was $6(P<0.001)$.

Conclusion: Exposure to tobacco smoke in utero may increase the pain-perception levels of newborns.

Keywords: intrauterine, newborn, pain perception, smoking, mother

\section{Introduction}

Though pain is subjective, it is a measurable concept. ${ }^{1,2}$ Perception of pain shows personal differences, and it is known that everybody's pain threshold is different. Painful stimuli cause a range of behavioral and physiological changes in the human body. These types of changes are used to score pain with the aid of various scales. ${ }^{3,4}$ Currently, pain management in clinics, especially intensive care units, is completed according to procedural administration of these scales. ${ }^{4}$ Neonatal pain management is also a very important issue. ${ }^{5}$ It is considered that neonatal pain has many unfavorable short- and long-term effects (eg, increased heart rate, decreased cognitive scores). ${ }^{6}$ Therefore, specific pain scales for preterm and term newborns are being developed. To decrease pain perception during invasive procedures, pharmacologic and nonpharmacologic methods are being considered. ${ }^{3}$

Scientific studies have attempted to determine the factors affecting the perception of pain. Smoking is one of these factors. While the increase in sensitivity to pain caused by smoking has not been fully explained pathophysiologically, it is thought that it affects the central nervous system, especially at the level of 
nicotinic acetylcholine receptors. ${ }^{7}$ Studies have shown that cigarette use increases the perception of pain in children and adults. ${ }^{8,9}$

Globally, though maternal use of cigarettes has reduced in recent years, it has been shown to be common still in recent research $(9 \%-46 \%) .{ }^{10}$ It is a known fact that intrauterine exposure to cigarettes has many negative effects in the prenatal, natal, and postnatal periods. ${ }^{11}$ However, there has been no study on the perception of pain by newborns born to mothers who smoked during pregnancy. Newborns are exposed to many painful procedures after birth, such as screening tests, vaccinations, and taking blood to check bilirubin levels. Each newborn may respond with different reactions based on their pain threshold when these types of interventions are carried out. ${ }^{12}$

In our study, we aimed to determine whether there was a difference in the pain-perception levels of newborns born to mothers who smoked during pregnancy and newborns born to mothers who were not exposed to active or passive smoking during pregnancy.

\section{Materials and methods}

After the study received permission from the ethics committee of Çanakkale Onsekiz Mart University, it was completed with newborns born at Çanakkale Onsekiz Mart University Medical Faculty Hospital between June 2013 and June 2014. Sixty consecutive newborns -30 in the exposed group and 30 in the unexposed group - were included in the study after informed written and verbal consent was obtained from parents.

\section{Study population}

A total of 30 newborns, 17 females and 13 males, born to mothers who stated that they had smoked at least five cigarettes per day during pregnancy, including the last trimester, were included in the exposed group. Inclusion criteria for mothers were giving birth at full term (37-42 weeks) by normal spontaneous vaginal delivery. Exclusion criteria for mothers were known chronic disease and alcohol or other drug usage. Inclusion criteria for newborns were normal birth weight $(2,500-4,000 \mathrm{~g})$, gestational age between 37 and 42 weeks, healthy, and fed with breast milk. Newborns with 5-minute Apgar score of 7 or below, given sedative or analgesic medications, with illness found on routine physical examination after birth, not fed orally, requiring neonatal resuscitation during birth, or those with mothers given sedative or narcotic medication for pain in the first 24 hours after birth were excluded from the study. A total of 30 newborns, 16 females and 14 males, born to mothers not exposed to active or passive smoking during pregnancy with same inclusion and exclusion criteria to the exposed group comprised the unexposed group.

\section{Procedure}

At 48 hours postdelivery and while prepping for discharge, newborns were breastfed for 30 minutes, then undressed and placed in supine position on a preheated radiant-heated open bed. For peripheral oxygen saturation $\left(\mathrm{SpO}_{2}\right)$ and heart-rate monitoring, a transcutaneous measurement probe was tied to the right ankle (Nellcor ${ }^{\mathrm{TM}} \mathrm{N}-560$ pulse oximeter). Video recording of the newborn began 1 minute before intervention by the same researcher. When the newborn was calm, a hepatitis B vaccination, routinely given after birth, in a 26 $\mathrm{G}(16 \mathrm{~mm})$ injector was administered intramuscularly at $90^{\circ}$ to the left lateral vastus muscle. Video recording continued for 2 minutes after the injection was finished. The injections were administered by the same experienced nurse, blind to the study group.

\section{Pain-score evaluation}

The camera recordings obtained were evaluated by the same researcher blind to the study at the end of the study. During the recording, the newborn's reactions before, during, and after injection were investigated. To evaluate these findings, the Neonatal Pain, Agitation, and Sedation Scale (N-PASS), which has adequate psychometric evidence for use in infants and children, was used. This scale is formed of five parameters: crying irritability, behavior, facial expression, tone of extremities, and vital signs $\left(\mathrm{SpO}_{2}\right.$, heart rate, respiration rate). Each parameter is rated with values of -2 , $-1,0,1$, or $2 .{ }^{13}$ The responses were evaluated as -2 for least response and 2 as most response. The values given for each parameter are added together to determine the total pain score for the newborn.

\section{Data analysis}

The scores from the N-PASS for the groups, together with characteristics for each newborn, were uploaded to SPSS 20 for Windows (IBM Corporation, Armonk, NY, USA). Descriptive statistics were calculated to summarize sample characteristics. Normal distribution of data was assessed using the Kolmogorov-Smirnov test. Continuous variables are shown as mean \pm standard deviation or median (range), where applicable. Mean differences between groups were compared with Student's $t$-test; otherwise, the MannWhitney $U$ test was applied for comparisons of the median values. Categorical data were analyzed by Pearson's $\chi^{2}$ or 
Fisher's exact test, where appropriate. A $P$-value of less than 0.05 was considered statistically significant.

\section{Results}

The characteristics of the total of 60 newborns in the exposed and unexposed groups are given in Table 1. Painperception scores for newborns of mothers who smoked

Table I Sample characteristics of the groups

\begin{tabular}{|c|c|c|c|}
\hline Characteristics & Group I, n=30 & Group 2, n=30 & $P$ \\
\hline & n (\%) & n (\%) & \\
\hline \multicolumn{4}{|l|}{ Sex } \\
\hline Male & 14 (46.7\%) & $13(43.3 \%)$ & 0.79 \\
\hline \multirow[t]{2}{*}{ Female } & $16(53.3 \%)$ & $17(56.7 \%)$ & \\
\hline & Mean \pm SD & Mean \pm SD & \\
\hline Birth weight, g & $3,208 \pm 434$ & $3,189 \pm 407$ & $0.86^{*}$ \\
\hline \multirow{2}{*}{$\begin{array}{l}\text { Gestational age, } \\
\text { weeks }\end{array}$} & $39.8 \pm 1.1$ & $39 \pm 1.2$ & $0.91 *$ \\
\hline & Median (range) & Median (range) & \\
\hline $\mathrm{SpO}_{2}$ decrease & $5(0-25)$ & $8.5(I-2 I)$ & $0.02^{* *}$ \\
\hline HR variability & II (I-28) & $18(4-50)$ & $<0.00 I^{* *}$ \\
\hline \multicolumn{4}{|c|}{ (\% rate of increase) } \\
\hline N-PASS score & $6(4-9)$ & $8.5(5-10)$ & $<0.00 I^{* *}$ \\
\hline
\end{tabular}

Notes: *Student's t-test; **Mann-Whitney $U$ test. Group I, intrauterine smokeunexposed group; group 2, intrauterine smoke-exposed group.

Abbreviations: $\mathrm{SD}$, standard deviation; $\mathrm{SpO}_{2}$, peripheral oxygen saturation; $\mathrm{HR}$, heart rate; N-PASS, Neonatal Pain, Agitation, and Sedation Scale. were significantly higher $(P<0.01)$ than pain scores of newborns born to mothers who did not smoke or were not exposed to passive smoking (Table 1, Figure 1). There was a difference of 2.5 points between the median scores of groups. There was a significant increase in heart rate and decrease in $\mathrm{SpO}_{2}$ of newborns of mothers who smoked (Table 1). The pain scores of the newborns were compared in terms of sex. There was no statistically significant difference in terms of pain scores of all the females and males in the exposed and unexposed groups $(P=0.97)$. When the females and males in the exposed group were compared among themselves and the females and males in the unexposed group were compared among themselves, there was no statistically significant difference in terms of pain scores ( $P=0.58, P=0.35$ ) (Table 2).

Table 2 N-PASS scores according to the sex of newborns

\begin{tabular}{llll}
\hline Groups & $\begin{array}{l}\text { N-PASS of } \\
\text { females, median } \\
\text { (range) }\end{array}$ & $\begin{array}{l}\text { N-PASS of } \\
\text { males, median } \\
\text { (range) }\end{array}$ & $P^{*}$ \\
\hline Group I & $5.5(4-7)$ & $6(4-9)$ & 0.42 \\
Group 2 & $9(6-10)$ & $8(5-10)$ & 0.65 \\
Group I and group 2 & $7(4-10)$ & $7(4-10)$ & 0.97 \\
\hline
\end{tabular}

Notes: *Mann-Whitney $U$ test. Group I, intrauterine smoke-unexposed group; group 2, intrauterine smoke-exposed group.

Abbreviation: N-PASS, Neonatal Pain, Agitation, and Sedation Scale.

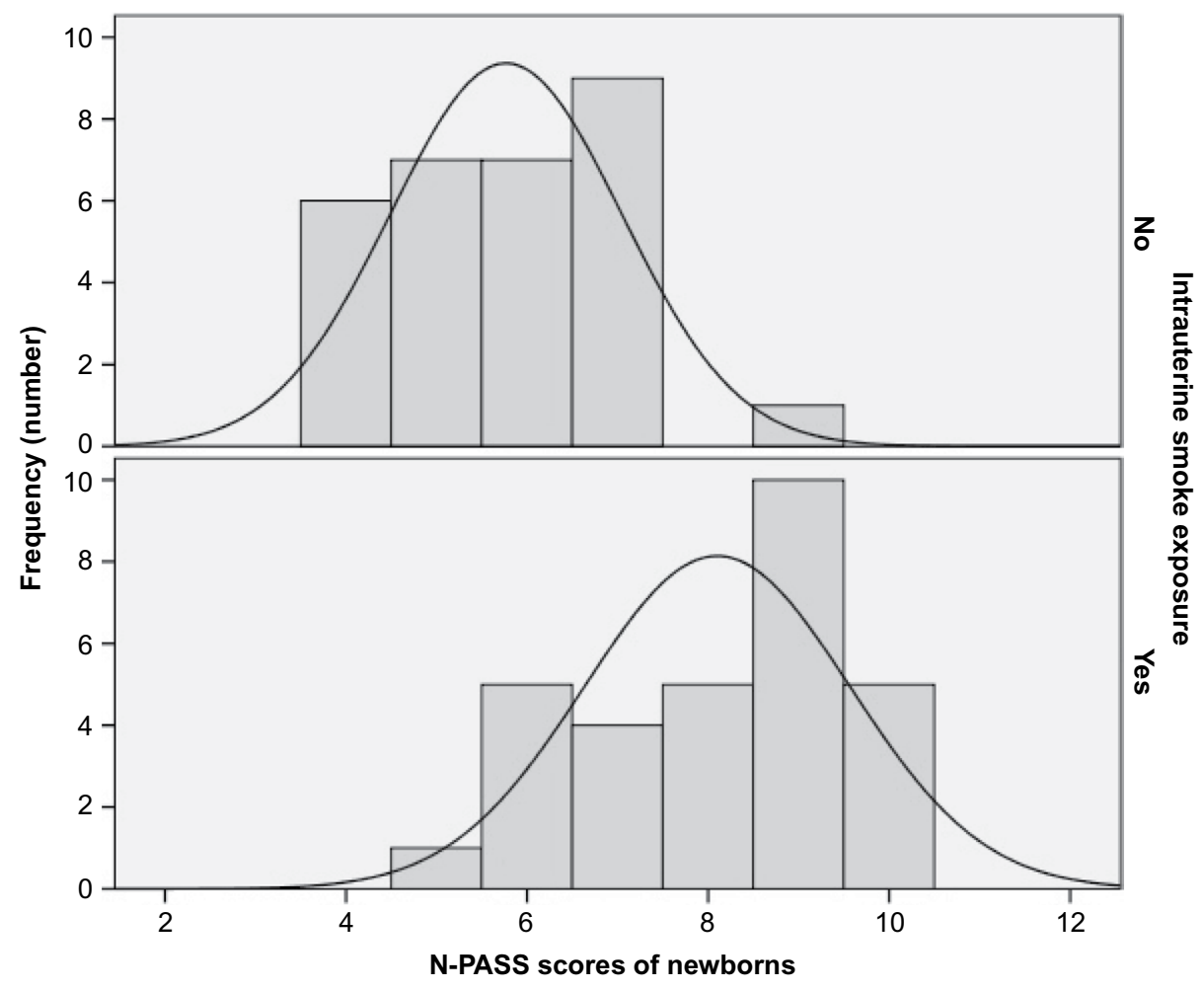

Figure I Neonatal Pain, Agitation, and Sedation Scale (N-PASS) scores of newborns.

Notes: N-PASS scores of the intrauterine smoke-unexposed group (top) - median 6; N-PASS scores of the intrauterine smoke-exposed group (bottom) - median 8.5. The difference between groups was statistically significant $(P<0.01)$. 


\section{Discussion}

We found the pain scores for newborns born to mothers who smoked were higher than those of newborns born to mothers who did not smoke or were not exposed to passive smoking. This difference in the scores means that newborns born to mothers that smoked cried more, experienced tachycardia, and had decreased $\mathrm{SpO}_{2}$. This result adds another new effect to the list of negative effects that smoking during pregnancy has on the newborn.

There has been no study published on smoking during pregnancy and pain-perception levels of newborns; however, there have been two studies showing that pain perception increases in smoking adults and children exposed to passive smoking compared to other individuals. ${ }^{8,9}$ It is known that cigarettes may cause chronic-pain syndromes. ${ }^{14}$ Although the mechanism of how cigarette exposure affects pain perception has not been fully explained, it is thought to be linked to the effect of smoking on central and peripheral nicotinic acetylcholine receptors. ${ }^{7}$ Prenatal cigarette use is known to cause many negative effects on the fetus, such as intrauterine growth retardation, early fetal loss, early rupture of membranes, and anomalies of placental location. ${ }^{10}$ It has also been shown that intrauterine cigarette exposure may cause effects in the period after birth, such as sudden infant-death syndrome, asthma, obesity, behavior disorders, and learning difficulties. ${ }^{15-18}$ These negative effects of maternal cigarette use are important arguments in the struggle against cigarette use during pregnancy. Increased pain perception of newborns may be useful when evaluated in this context.

Preventing pain in newborns, the most sensitive individuals in society, is very important, both ethically and physiologically. In newborns, pain causes increased heart rate, a decrease in $\mathrm{SpO}_{2}$ physiologically, and autonomic changes, such as sweaty palms, especially in term newborns. ${ }^{4}$ Additionally, greater exposure to procedural pain has been linked to decreased cognitive and motor scores, growth impairment, decreased white matter and subcortical gray matter, and maturation and alteration of the structure of the corticospinal tract. ${ }^{19}$ As a result, resolving pain or removing factors that increase pain perception when newborns are exposed to many necessary procedures involving invasive interventions (like vaccinations) in the infant period is important for the quality of life of both the baby and the family.

There may be a correlation between smoking mothers and infantile colic in newborns in the postnatal period. In one study, it was suggested that nicotine metabolites in cord blood or breast milk may affect motilin levels in newborns, possibly causing colic pain. ${ }^{20}$ The results found in our study, that newborns of mothers who have smoked have increased pain perception, may be related to the course of infantile colic in these infants.

\section{Limitations}

Our study has some limitations. First, it does not explain whether the increased pain perception of newborns after birth changes over time or not. Therefore, prospective controlled studies will be appropriate. Second, the pain perception of newborns born to mothers with certain passive-smoking exposure confirmed by measuring the nicotine metabolites in cord blood could be investigated. However, in the literature it has been shown that maternal reports on passive smoking of their infants were reliable and acceptable. ${ }^{21}$ Lastly, painassessment tools scoring pain expression do not exactly reflect nociception. However, while verbal children can describe the intensity of the pain, nonverbal infants express their pain as behavior response. Although it is proposed that the higher scores reflect the higher intensity of pain, there is not an exact consensus on this. ${ }^{22,23}$

\section{Conclusion}

Intrauterine tobacco exposure may increase the pain perception of newborns. Precautions to prevent exposure to smoking, a preventable risk factor, should be an important public health target. Informing candidates for pregnancy who smoke about this topic may contribute to reducing the use of cigarettes in pregnancy.

\section{Disclosure}

The authors report no conflicts of interest in this work.

\section{References}

1. Anand KJ, Aranda JV, Berde CB, et al. Summary proceedings from the neonatal pain-control group. Pediatrics. 2006;117:S9-S22.

2. Lago P, Garetti E, Merazzi D, et al. Guidelines for procedural pain in the newborn. Acta Paediatr 2009;98:932-939.

3. Hummel P, Puchalski M, Creech SD, Weiss MG. Clinical reliability and validity of the N-PASS: neonatal pain, agitation and sedation scale with prolonged pain. J Perinatol. 2008;28:55-60.

4. Franck LS, Miaskowski C. Measurement of neonatal responses to painful stimuli: a research review. J Pain Symptom Manage. 1997;14:343-378.

5. McKechnie L, Levene M. Procedural pain guidelines for the newborn in the United Kingdom. J Perinatol. 2008;28:107-111.

6. Grunau RE, Holsti L, Peters JW. Long-term consequences of pain in human neonates. Semin Fetal Neonatal Med. 2006;11:268-275.

7. Shi Y, Weingarten TN, Mantilla CB, Hooten WM, Warner DO. Smoking and pain: pathophysiology and clinical implications. Anesthesiology. 2010;113:977-992. 
8. Topaloğlu N, Tekin M, Yıldırım S, Küçük A, Gönüllü B, Hancı V. Passive smoking increases pain perception in children undergoing venous catheterization. Acta Paediatr. 2013;102:e493-e496.

9. Hanci V, Kiraz HA, Omür D, et al. [Effects of smoking on venous cannulation pain: a randomized prospective trial]. Rev Bras Anestesiol. 2015;65:47-50. Portuguese.

10. Tong VT, Dietz PM, Morrow B, et al. Trends in smoking before, during, and after pregnancy - Pregnancy Risk Assessment Monitoring System, United States, 40 sites, 2000-2010. MMWR Surveill Summ. 2013;62:1-19.

11. Salihu HM, Wilson RE. Epidemiology of prenatal smoking and perinatal outcomes. Early Hum Dev. 2007;83:713-720.

12. Porter FL, Wolf CM, Miller JP. Procedural pain in newborn infants: the influence of intensity and development. Pediatrics. 1999;104:e13.

13. Hummel P, Puchalski M, Creech S, Weiss MG. N-PASS: Neonatal Pain, Agitation, and Sedation Scale: reliability and validity. Poster presented at: Pediatric Academic Societies Annual Meeting; May 3-6, 2003; Seattle, WA.

14. Weingarten TN, Moeschler SM, Ptaszynski AE, Hooten WM, Beebe TJ, Warner DO. An assessment of the association between smoking status, pain intensity, and functional interference in patients with chronic pain. Pain Physician. 2008;11:643-653.

15. Shah T, Sullivan K, Carter J. Sudden infant death syndrome and reported maternal smoking during pregnancy. Am J Public Health. 2006;96:1757-1759
16. Thacher JD, Gruzieva O, Pershagen G, et al. Pre- and postnatal exposure to parental smoking and allergic disease through adolescence. Pediatrics. 2014; 134:428-434.

17. Wang L, Mamudu HM, Wu T. The impact of maternal prenatal smoking on the development of childhood overweight in school-aged children. Pediatr Obes. 2013;8:178-188.

18. Indredavik MS, Brubakk AM, Romundstad P, Vik T. Prenatal smoking exposure and psychiatric symptoms in adolescence. Acta Paediatr. 2007;96:377-382.

19. Walker SM. Neonatal pain. Paediatr Anaesth. 2014;24:39-48.

20. Shenassa ED, Brown MJ. Maternal smoking and infantile gastrointestinal dysregulation: the case of colic. Pediatrics. 2004;114: e497-e505.

21. Matt GE, Hovell MF, Zakarian JM, Bernert JT, Pirkle JL, Hammond SK. Measuring secondhand smoke exposure in babies: the reliability and validity of mother reports in a sample of low-income families. Health Psychol. 2000;19:232-241.

22. Hummel P. Psychometric Evaluation of the Neonatal Pain, Agitation, and Sedation Scale (N-PASS) Tool in Infants and Children Age One to Thirty-Six Months in the Post-anesthesia Care Unit [doctoral thesis]. Chicago: Loyola University Chicago; 2014.

23. Thewissen L, Allegaert K. Analgosedation in neonates: do we still need additional tools after 30 years of clinical research? Arch Dis Child Educ Pract Ed. 2011;96:112-118.

\section{Journal of Pain Research}

\section{Publish your work in this journal}

The Journal of Pain Research is an international, peer reviewed, open access, online journal that welcomes laboratory and clinical findings in the fields of pain research and the prevention and management of pain. Original research, reviews, symposium reports, hypothesis formation and commentaries are all considered for publication.

\section{Dovepress}

The manuscript management system is completely online and includes a very quick and fair peer-review system, which is all easy to use. Visit http://www.dovepress.com/testimonials.php to read real quotes from published authors. 